\title{
Extreme Learning Assistants: The Impact of an Authentic Teaching Experience on Undergraduate Physics Majors
}

\author{
Lauren A. Harris, Ian D. Beatty and William J. Gerace \\ Department of Physics and Astronomy, University of North Carolina at Greensboro, \\ PO Box 26170, Greensboro NC 27610
}

\begin{abstract}
UNCG has an innovative Learning Assistant (LA) program, in which upper-class undergraduate physics majors teach laboratory sections of the introductory calculus-based physics sequence. The lecture section's professor provides supervision and determines the overall learning objectives and structure of the labs, but the team of LAs develop the detailed lesson plans, write up all handouts and quizzes, conduct the lab sessions, and evaluate student work. This gives the LAs a genuine voice in planning and teaching, and increases the authenticity of the teaching experience. In order to investigate the impact of this teaching experience upon physics majors, we interviewed five current and former LAs. We analyzed the interview transcripts via emergent thematic analysis to identify the most prevalent impacts, and then viewed the results through the lens of professional identity development. We claim that the LA experience helps grow three aspects of physics majors' professional identity: their sense of themselves as a physics teacher, as a physics student, and as a member of a community of practice.
\end{abstract}

Keywords: Learning Assistants, Teaching Assistants, Undergraduate Instructors, Laboratory Instruction, Identity PACS: 01.40.Fk, 01.50.Qb, 01.40.gb, 01.40.jc.

\section{INTRODUCTION}

"Learning Assistant" (LA) is an increasingly common term for an upper-class undergraduate student that works with the instructor of an introductory course to help students learn, generally by interacting with students to support active learning approaches. Many schools use LAs within lecture or discussion sections to facilitate small-group discussion. In one pattern of LA use, an instructor or worksheet poses a question or problem to the class, and LAs join groups and use Socratic questioning methods to help the students think and discuss productively [1-4]. Some programs also use LAs outside of class to provide feedback on writing, lead small group discussions, or engage in other one-on-one small group interactions. The term "Learning Assistant" implies more than just the use of undergraduates as teaching assistants, however; LA programs include explicit instruction for the LAs in research-based pedagogical strategies and tactics, and are aimed at recruiting students into a teaching profession. LA programs often include a formal pedagogy course for participants $[5,6]$.

In the Department of Physics and Astronomy at the University of North Carolina at Greensboro (UNCG), we have instituted an "extreme" LA program in which a small team of LAs is given almost complete responsibility for the two laboratory sections associated with each of the two introductory calculus-based physics courses. The faculty member in charge of the lecture portion of the course, one of the Department's two Physics Education Research faculty (the second and third authors of this paper), supervises the laboratory sections. This individual sets the overall learning objectives, schedule of topics, and grading system for the labs. The team of LAs is responsible for developing the detailed plans for each lab meeting; generating syllabi, lab instructions, reference materials, quizzes, and other documents; conducting the lab meetings; and evaluating student work. The faculty member may occasionally drop in on lab meetings to gauge their tone and to help troubleshoot any difficulties that have cropped up, but generally keeps a low profile and is careful not to undercut the LAs' authority and credibility.

Each semester, the LA team meets with the supervising faculty member a few times during the week or two before classes begin, as well as once or twice a week over the course of the semester. In the meetings during the semester, the supervisor debriefs the LAs on how the prior round of lab meetings went, and they all discuss, diagnose difficulties, and identify changes for the future. They then develop plans for the upcoming labs, with the faculty member setting overall goals and the LAs developing the details of implementation. During all meetings, discussions focus on pedagogy as well as laboratory design and logistics. Difficulties that have arisen are often used as opportunities for the LAs to learn about pedagogy. The LAs are typically quite familiar with research-based active-learning methods, at least from a student's perspective, from having taken 
several courses taught by the PER faculty. Thus, these meetings provide an excellent opportunity to have LAs reflect on the courses they have taken and come to understand why they were taught as they were.

UNCG's LA program began in Fall 2010 with two third-year Physics majors, who were observed every class and mentored by a Science Education graduate student. It has since evolved into a system in which the team typically consists of two veterans and two rookies in any given semester. The course sequence is scheduled so that Physics I is offered every spring, and Physics II every fall. Each spring, the faculty review the roster of students who have completed Physics II the previous fall, and identify promising candidates for the LA program based on physics comprehension, approach to physics learning, interpersonal skills, attitude, and reliability. Those candidates are invited to join the program right away or the following fall. The rookies begin by observing, by circulating among and interacting with student lab groups, and by contributing their perceptions and recollections during planning meetings. As their familiarity with the pedagogical approach and their self-confidence grow, they gradually - at whatever pace each is comfortable with-take increasing responsibility, until the rookies are doing most of the instruction and discussion-leading during lab meetings, and the veterans are observing, mentoring as needed, and assisting with small-group support. (Sometimes, the unexpected departure of a team member will impel a rookie to step up to a higher level of responsibility unusually early, and/or cause us to recruit an additional member.)

This program was designed and developed largely to provide physics majors with a highly authentic and reflective teaching experience, in the belief that this would positively impact the LAs in a variety of ways and perhaps foment increased interest in teaching as a profession. In this paper, we describe a preliminary, qualitative investigation into the various ways that past and present LAs perceive they have been impacted by their participation in the program. Evidence of positive impacts can help us and others to justify the existence of such LA programs, and also to improve the design of these programs to be more effective.

\section{DATA COLLECTION AND ANALYSIS}

In order to investigate the perceptions of physics majors serving as LAs, we developed a semi-structured interview consisting of the following seven questions:

1) General overview, what was your opinion of being an LA?

2) How has being an LA affected the way you think about physics?
3) How has being an LA affected the way you think about teaching?

4) The program has evolved from being two LAs to being a team of multiple LAs with less traditional labs. Knowing the evolution of the program, do you think it's more effective now? How so?

5) How do you think the students feel about having an undergraduate teach?

6) Background on other LA programs: The LAs typically have weekly meetings with professors and each other as well as educational lectures. First, LAs lead learning teams (sometimes in recitation sections) in which students work collaboratively to make sense of physical problems posed in curriculum activities. Second, LAs work within the large lecture setting where they facilitate group interactions by helping students engage in debates, arguments, and forming consensus around conceptual questions that are posed roughly every $20 \mathrm{~min}$ of lecture typically through personal response systems (clickers) used to poll the class. Any comments on how our program compares to other LA programs?

7) Has this made you want to be a teacher, or at least opened your eyes to that field?

Questions 4, 5, and 6 did not provide data relevant to the objectives of this particular analysis. Therefore, in the remainder of this paper we discuss responses to questions $1,2,3$, and 7 .

At the time the interviews for this study were conducted, ten physics majors had participated as LAs since the program's inception. We interviewed five of these, selecting all students who were still on campus or in the geographic region, and who had either served for more than one semester as an LA or had just completed their first semester and planned to continue. They were provided no compensation or other incentive to participate. Three of the volunteers were interviewed individually, and two were interviewed together. Two of the five were interviewed at the end of their first semester as rookies, one at the end of his final year as a veteran, and two after they had graduated and begun a graduate program at UNCG (one in Mathematics and one in Nanoscience).

Interviews typically lasted 15-20 minutes, and were audio-recorded with the interviewee's permission. We transcribed responses to the four relevant questions identified above, omitting off-topic digressions. One of us (Harris) then conducted a thematic analysis of these transcriptions, comparing all responses to identify common themes that are "emergent" from the data rather than imposed by any specific theoretical frame- 
work. For this preliminary and exploratory study, no inter-rate reliability check was conducted.

\section{RESULTS}

Through our thematic analysis, we identified four themes that all or almost all respondents articulated. We also identified one theme that two respondents raised, and two that only one stated. We are including these latter three in our discussion because although only a minority of the respondents explicitly volunteered them during the recorded interviews, they are consistent with remarks made during un-recorded conversations, and in some cases seemed implicit but evident in other responses. In this section, we present the seven themes, along with example quotes indicating how they were articulated.

Theme 1, articulated by all five respondents, is an increased understanding of what teaching entails. As one respondent put it, "[We as LAs] actually get to experience what it's like, because we, at points during the weekly meetings, in preparation for these classes we were writing up our own projects, our own homework assignments or our own quizzes... That's what you're going to do as a professor as you develop your curriculum." Another, who is currently seeking employment as a teacher, said "I feel like I know what I'm getting myself into [with teaching]."

Theme 2 was also expressed by all five respondents: an increased interest in teaching. While not all are currently pursuing a teaching career, all suggested that they have thought more about becoming a teacher as a result of the LA program, and would not be opposed to teaching in the future. One of the respondents has chosen to pursue graduate study in Physics Education Research. Another commented that "[the LA program] definitely opened my eyes to [teaching] as more of a consideration for a potential career."

All five respondents also articulated theme 3: a better and/or different conceptual understanding of physics. All claimed that the program has given them a stronger understanding of the physics concepts, and some said that being a LA pushed them to study harder or to change their approach to learning in order to understand physics better. Some said that they not only felt like they understood physics better, but that they now frame their understanding in a different way. One said, "It's forced me to try to find a deeper understanding to manipulate the ideas more behind what physics is and all of the concepts." Another said, "teaching requires you to get the whole view, to look at the subject and instead of just knowing it for a test or for homework but to think about how you would explain this to another human being in a way that they can understand as well." Yet another said, "I want to organize [new information] in such a way that I would be teaching it to someone."

Theme 4 is enjoyment of the experience of being a $L A$. This was explicitly stated by four of the five respondents. It was also apparent in the general comments and manner of the fifth respondent, who has verbalized it outside of the recorded interview. Example quotes include, "It was a fun experience," and "I thoroughly enjoyed it." Some were specific about what aspects of the experience were fun, for example, "Interacting with students was a lot of fun," and "I liked hearing other students' thought process about why they reasoned the way they did."

Theme 5 was mentioned by two of the respondents: improved experimental skills. One stated, "I learned a lot about lab techniques that I sort of didn't get a good appreciation for when I was in the lab itself." This same respondent later stated, "[The LA program] definitely exposed me to... knowing more about why we do what we do in lab."

Theme 6 , articulated by only one respondent but consistent with un-recorded comments by other respondents and LAs, is: a stronger sense of community with peers. The respondent who identified it claimed that he typically studied alone before joining the LA program. He said, "I made better friends with the other LAs, which was cool to have connections in the physics department that I didn't have before." All three authors of this paper have observed that the LAs form a tightly-knit group for both studying and socializing.

Theme 7, also explicit in only one respondents' recorded comments but consistent with other interactions, is: increased self-confidence. That respondent said, "Being up there and teaching people showed me that I, most of the time, knew more than I gave myself credit for." That same respondent also said that teaching "really helped me get over my fear of public speaking."

\section{SUMMARY AND DISCUSSION}

We have identified four different kinds of impact that seem widespread, possibly universal, among participants in this "extreme" LA program: an increased understanding of what teaching entails, an increased interest in teaching, a better and/or different conceptual understanding of physics, and enjoyment of the experience of being a $L A$. We have identified three other impacts that exist for at least some participants, and seem likely to be widespread: improved experimental skills, a stronger sense of community with peers, and increased self-confidence.

It may be fruitful to view these impacts through the theoretical lens of identity development [7]: that is, from the perspective that education is (or should be) about developing a sense of identity as a professional- 
to-be (e.g., a teacher or a scientist) and as an apprentice to a professional community, not just about learning content knowledge.

Our seven themes suggest that participation in the LA program strengthens three different kinds or components of professional identity in our physics majors. One component is each student's identity as a physics teacher, indicated by themes 1 (increased understanding of what teaching entails) and 2 (increased interest in teaching). A second component is his or her identity as a science student, indicated by themes 3 (better and/or different conceptual understanding of physics) and 5 (improved experimental skills). A third component is his or her identity as a member of a community of practice, indicated by theme 6 (stronger sense of community with peers). Theme 7 (increased selfconfidence) is ambiguous, and might apply to any or all of these identity components, but seems likely to strongly signal growth in at least one. Theme 4 (enjoyment of the experience of being an LA) is also ambiguous. It might quite plausibly reflect the intrinsic reward of growth in one or more of these identity components, though it could also indicate nothing more than enjoyable activity and interaction. (We note, however, that shared fun can be a powerful mechanism for building bonds among members of a group, and are inclined to hypothesize a link between theme 4 and the strengthening of LAs' identity as a member of a community of practice.)

Harzai, Sonnert, Sadler, and Shanahan [8] have developed a "framework for students' identification with physics" that includes four components: recognition by others as being a "good" physics student; interest, the desire and curiosity to think about and understand physics; competence, the belief in one's ability understand physics content; and performance, the belief in one's ability to perform required physics tasks. They have found these constructs to be productive, in that physics student identity, so defined, correlates positively with an intended career in physics and several similar variables. We find it suggestive that the LA program inherently provides the LAs with recognition, by virtue of their recruitment and status as instructors, while our findings point to an increase in LAs' sense of competence and performance as well-as physics students, and as teachers. Our results also indicate an increase in students' interest in teaching, though they do not clearly signify an increased interest in physics itself (aside from "learning it differently").

Motivated by our preliminary findings, we see an opportunity to conduct a more extensive follow-up study to specifically investigate the effects of this LA program on physics student identity development, as viewed through one or more identity frameworks. Such a study should involve detailed and longitudinal ethnographic or case study data collection to better elicit the mechanisms and impacts of "being a LA," as well as data collection and analysis deliberately targeting the constructs of the framework(s). More generally, we see a need to study the impacts of LA programs upon participants at several different institutions with different LA program implementations, in order to identify the program features most important and valuable.

Based on this preliminary study, however, we can conclude that the present UNCG Physics LA program does in fact have several positive impacts on participants' perceptions of themselves as potential teachers and as physics learners, as it was intended to.

\section{ACKNOWLEDGMENTS}

We wish to thank the current and former UNCG Learning Assistants who agreed to be interviewed for this study. We are also grateful to Dr. Eleanor Sayre for her suggestions and advice, especially regarding professional identity development in physics students.

\section{REFERENCES}

1. V. Otero, S. Pollock and N. Finkelstein, Am. J. Phys. 78(11), 1218-1224 (2010)

2. V. Otero, N. Finkelstein, R. McCray and S. Pollock, Science 313(5786), 445-446 (2006).

3. J. E. Groccia and J. E. Miller, Innovative Higher Ed. 21(2), 87-100 (1996).

4. K. E. Gray, D. C. Webb, and V. K. Otero, AIP Conference Proceedings 1413, 199-202 (2012).

5. G. Stewart, APS Forum on Education Summer 2006 Newsletter (E. Malamud, ed.), pp. 36-37 (2006).

6. V. Otero, S. Pollock, and N. Finkelstein, Am. J. Phys. 17(11), 1218-1220 (2010).

7. E. Wenger, Communities of Practice: Learning, Meaning, and Identity, (Press Syndicate of the University of Cambridge, Cambridge, 1998), pp. 149-150.

8. Z. Hazari, G. Sonnert, P.M. Sadler and M.-C. Shanahan, J. Research Sci. Teaching 47(8) 978-1003 (2010). 